\title{
Comparison Studies on Dynamic Packaging Properties of Corrugated Paperboard Pads
}

\author{
Yanfeng Guo ${ }^{1}$, Wencai $\mathrm{Xu}^{2}$, Yungang $\mathrm{Fu}^{1}$, Wei Zhang ${ }^{1}$ \\ ${ }^{1}$ Department of Packaging Engineering, Xi'an University of Technology, Xi'an, China \\ ${ }^{2}$ Department of Packaging Engineering, Beijing Institute of Graphic Communication, Beijing, China \\ E-mail: \{guoyf,fygpack, zhang_wei\}@xaut.edu.cn,xuwencai@263.net \\ Received December 17, 2009; revised February 23, 2010; accepted February 26, 2010
}

\begin{abstract}
Corrugated paperboard is a kind of inexpensive and environmental-friendly packaging material, and may be made into pads of package cushioning to protect products from shock and vibration damage by isolation during distribution. This article deals with the characterization of dynamic packaging properties of corrugated paperboard pads, such as dynamic cushioning curves, vibration transmissibility and frequency curves. The main feature of article is the evaluation on the dynamic shock cushioning property and vibration transmissibility of corrugated paperboard pads by a series of experimental studies on the drop shock tester and vibration tester, the establishment of experimental formulas of dynamic cushioning curves, and the analysis of resonance frequencies and vibration transmissibility. By using the fitting polynomial of curve and method of the least mean square, the experimental formulas with third order polynomial function of dynamic cushioning curves for corrugated paperboard pads are obtained. By using linear vibration theory with single degree of freedom, the resonance frequencies, vibration transmissibility and damping ratios of corrugated paperboard pads at different static loads are acquired. All results show the dynamic properties relevant to design applications of corrugated paperboard pads for protective packaging.
\end{abstract}

Keywords: Corrugated Paperboard Pads, Dynamic Shock Cushioning Property, Dynamic Cushioning Curve, Vibration Transmissibility, Resonance Frequency

\section{Introduction}

Corrugated paperboard is a kind of inexpensive and environmental-friendly packaging material with corrugated sandwich structure, holds lightweight, high strength-toweight and stiffness-to-weight ratios, and has economic and environmental advantages over plastic foams [1,2]. It also has excellent machining technology of packaging, and may be made into pads of package cushioning to protect products from shock and vibration damage by isolation during distribution. The usual technology is to interpose the corrugated paperboard pad between the product and the container to provide the necessary isolation [3-5]. So, there is an increasing interest in utilizing corrugated paperboard pads for protective packaging of products (e.g. precise equipment and instrument, household appliance and fragile goods etc).

For corrugated paperboard, the compressive strength, crush strength, bending defection and flexural stiffness, creep property and recoverability were investigated by
Hahn, Lee, Urbanik, Guo et al. [6-9]. By using some finite element models and commercial finite element code ABAQUS or ANSYS, the mechanical behaviors of corrugated paperboard such as buckling, transverse shear, elasticity, stability, collapse and ultimate failure were studied by Gilchrist, Nordstrand, Aboura, Rami, Talbi et al. [10-14]. Within the finite element models (e.g. thin shell element, simplified homogenization model), both geometric nonlinearity (large deformation) and material nonlinearity (anisotropy or orthotropy) effects were considered. The cushioning property and its predictive model, the vibration transmissibility and frequency response of single-wall corrugated paperboard were analyzed by Sek et al. $[15,16]$. But for the corrugated paperboard pads (e.g. single layer pad, two layers pad, three layers pad), the lack of dynamic packaging properties such as dynamic cushioning curves and vibration transmissibility hampers its application for protective packaging of products [4-5]. Therefore the aims of this research work are as follows: Firstly, evaluate the dy- 
namic shock cushioning property of corrugated paperboard pads by drop shock tests, and establish the experimental formulas of dynamic cushioning curves. Secondly, study the vibration transmissibility of corrugated paperboard pads at different static loads by vibration tests, and analyze the resonance frequencies, vibration transmissibility and damping ratios.

\section{Structure of Corrugated Paperboard Pads}

The structure of corrugated paperboard pads usually covers single layer corrugated paperboard pad in Figure 1(a), two layers corrugated paperboard pad in Figure 1(b), and three layers corrugated paperboard pad in Figure 1(c). The difference of these pads is the layer quantity (or thickness of pad). The thicknesses of single layer pad, two layers pad, three layers pad are $7.81 \mathrm{~mm}$, $15.62 \mathrm{~mm}$ and $23.43 \mathrm{~mm}$, respectively. The top surface of all test specimens is square, and the dimension is $15 \mathrm{~cm} \times 15 \mathrm{~cm}$. They would be respectively called single layer pad, two layers pad, three layers pad for short.

These corrugated paperboard pads are also made of double-wall corrugated paperboard with $\mathrm{A}$ and $\mathrm{B}$ flutes by machining technology of cutting, folding and pasting. The single layer pad is directly made of the double-wall corrugated paperboard, the structure of two layers pad comprises two layers of the double-wall corrugated paperboard, and the structure of three layers pad consists of three layers of the double-wall corrugated paperboard. The thickness of double-wall corrugated paperboard with A and B flutes is $7.81 \mathrm{~mm}$, the corrugated cores and inner sheet are corrugated paper with grammage of $150 \mathrm{~g} / \mathrm{m}^{2}$, and the face sheets are kraft linerboard with grammage of $250 \mathrm{~g} / \mathrm{m}^{2}$. Before each of tests, all test

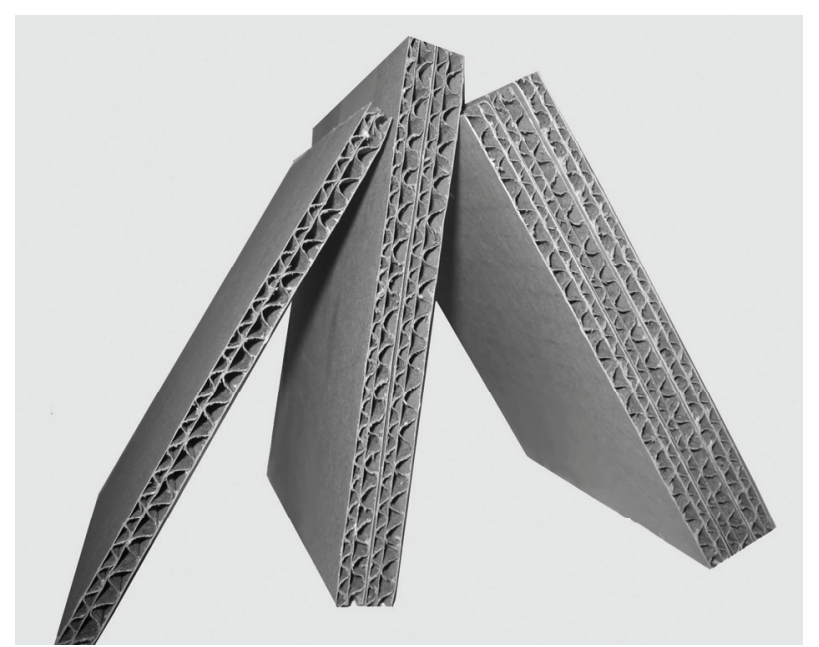

(a)

(b)

(c)

Figure 1. Photograph of corrugated paperboard pads. specimens of corrugated paperboard pads should be preconditioned to equilibrium in air uniformly maintained for at least 24 hours at ambient temperature $23^{\circ} \mathrm{C}$ and relative humidity $60 \%$.

\section{Description of Dynamic Packaging Properties}

\subsection{Description of Dynamic Shock Cushioning Property}

The dynamic shock cushioning property describes the capability of absorbing drop shock energy of corrugated paperboard pads, and reflects the relationship between peak acceleration and static stress during drop shock. The peak acceleration is a non-dimension ratio of peak acceleration of the packaged item to gravity acceleration. It is usually presented as a family of dynamic cushioning curves (or peak acceleration and static stress curve), which shows peak acceleration during drop shock for a range of static loads and is constructed for several drop heights [3]. The test system for dynamic shock cushioning property (Figure 2) shall consist of a drop shock tester, a signal acquisition \& processing device, a set of Data Acquisition \& Signal Processing Engineering Technology (DASP-ET) software. The drop shock tester has a drop block and weight (to represent the packaged item) and impact base for dynamic loading of a test specimen to simulate drop shock in handling. The weight is mounted on the drop block. The mass of weight and drop height of the drop block are adjustable. An acceleration sensor is mounted on the drop block, and the signal output from the acceleration sensor is firstly fed into the signal acquisition \& processing device, then the drop shock acceleration and time curve may be read and displayed by DASP-ET.

While the drop block with the weight impacts the test specimen of corrugated paperboard pad from a predetermined drop height by means of area contact, according to the law of conservation of energy, the potential energy of weight and drop block shall be transferred as the kinetic energy of weight and drop block and the deformation energy of test specimen [3]. The relationship may be described as the following expression

$$
\frac{1}{2} m V^{2}+A T \int_{0}^{\varepsilon} \sigma(\varepsilon) d \varepsilon=m g(h+T \varepsilon)
$$

where $m$ stands for mass of drop block and weight, $V$ is impact velocity of weight and drop block, $A$ is contact area between test specimen and drop block, $T$ is thickness of test specimen, $\sigma$ and $\varepsilon$ are compression stress and strain of test specimen, and $h$ is a predetermined drop height. When the impact velocity of weight and drop block becomes zero $(V=0)$, the maximum deformation 


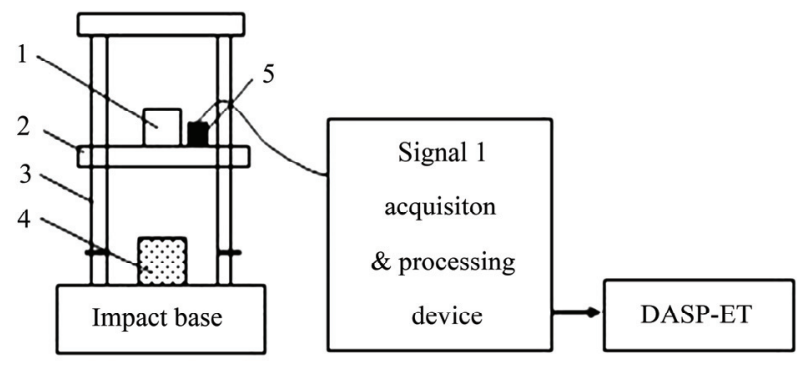

Figure 2. Test system of dynamic shock cushioning property: 1.Weight; 2.Drop block; 3.Guide column; 4.Test specimen 5. Acceleration sensor.

$\varepsilon_{m}$ of test specimen is reached, and the maximum stress $\sigma_{m}$ of test specimen and peak acceleration $G_{m}$ would be occurred, and Equation (1) may be rewritten as

$$
\int_{0}^{\varepsilon_{m}} \sigma(\varepsilon) d \varepsilon=\frac{m g}{A}\left(\frac{h}{T}+\varepsilon_{m}\right)=\sigma_{s}\left(\frac{h}{T}+\varepsilon_{m}\right)
$$

where $\sigma_{s}$ is static stress exerted on test specimen. In addition, according to the Newton's law of motion, the maximum force exerted on weight and drop block equals to its inertial force plus its own weight [3], and the relationship may be written as

$$
\sigma_{m}=\left(G_{m}+1\right) \sigma_{s}
$$

where $G_{m}$ is peak acceleration divided by gravity acceleration g. Then substituting Equation (3) into Equation (2), the following expression may be derived

$$
G_{m}=\frac{\sigma_{m}}{\int_{0}^{\varepsilon_{m}} \sigma(\varepsilon) d \varepsilon}\left(\frac{h}{T}+\varepsilon_{m}\right)-1
$$

where $\frac{\sigma_{m}}{\int_{0}^{\varepsilon_{m}} \sigma(\varepsilon) d \varepsilon}$ is the ratio of maximum stress to unit volume stored energy. It is obvious that peak acceleration may directly indicate the capability of absorbing drop shock energy of corrugated paperboard pad, and may express the dynamic shock cushioning property of corrugated paperboard pad. So the dynamic cushioning curve has proved to be the most practical basis for describing the dynamic shock cushioning property, the lower the dynamic cushioning curve swings, and the better protection the package cushioning provides $[4,5]$.

\subsection{Description of Vibration Transmissibility}

The vibration transmissibility is usually described as the relationship between vibration transmissibility and resonance frequency of corrugated paperboard pads at different static loads. Vibration transmissibility is a non-dimension ratio of response acceleration amplitude of the packaged item in steady-state forced vibration to excitation acceleration amplitude [3]. The test system for vibration transmissibility (Figure 3) shall consist of a dynamoelectric vibration tester, a signal acquisition \& processing device, a set of DASP-ET software. Two test specimens combination under investigation are placed in the test fixture, and the mass block is placed on the bottom test specimen. The two test specimens, mass block (to represent the packaged item) and fixture are mounted on the vibration tester. The weight of mass block is changeable, and the static load exerted on the bottom test specimen may be adjusted by changing the weight of mass block. One acceleration sensor is attached to the platform of vibration table to monitor the excitation acceleration, and the other is located in the mass block to measure the response acceleration. The signal outputs from the sensor located in the mass block and on the platform of vibration table are simultaneously fed into the signal acquisition \& processing device, then the experimental data shall be analyzed and presented in the form of vibration transmissibility and frequency curve by DASP-ET.

Although most package cushioning materials exhibit nonlinear property, a brief discussion of linear system with single degree of freedom will aid in understanding some of the fundamental aspects of vibration as related to packaging considerations $[4,5]$. For the vibration test system in Figure 3, the mass block cushioned on the test specimen may be idealized as the linear single degree of freedom system with viscous damping, and the vibration transmissibility $T_{r}$ of package cushioning system with corrugated paperboard pads would be described as

$$
T_{r}=\sqrt{\frac{1+(2 \xi \lambda)^{2}}{\left(1-\lambda^{2}\right)^{2}+(2 \xi \lambda)^{2}}}
$$

where $\lambda$ stands for frequency ratio $\left(\lambda=f / f_{r}\right), f$ is excitation frequency of vibration table, $f_{r}$ is resonance frequency of the package cushioning system, and $\zeta$ represents damping ratio. It is evident that vibration transmissibility has a close relationship with frequency ratio and damping ratio. When the resonance takes place $(\lambda=1)$, the damping ratio $\zeta$ may be derived from Equation (5) and written as

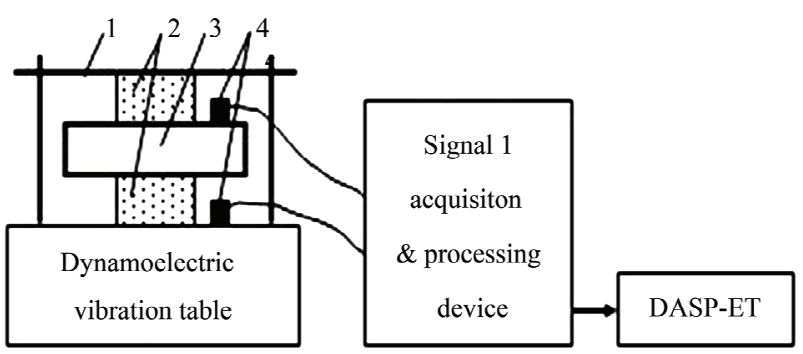

Figure 3. Test system of vibration transmissibility: 1) Clamp device; 2) Test specimens; 3) Mass block; 4) Acceleration sensors. 


$$
\xi=\frac{1}{2} \sqrt{\frac{1}{T_{r}^{2}-1}}
$$

So, after obtaining the vibration transmissibility and frequency curves of corrugated paperboard pads by vibration tests with slow sine sweep, resonance frequencies, vibration transmissibility and damping ratios may be analyzed, and the vibration transmissibility of corrugated paperboard pads shall be comprehensively evaluated.

\section{Experimental Methods of Dynamic Packaging properties}

The most comprehensive method for determining dynamic shock cushioning property is described in the standard ASTM D 1596 "Standard test method for dynamic shock cushioning characteristics of packaging materials". The test procedure is as follows: Firstly, position the test specimen on the impact base and prepare the drop block to impact the test specimen. Secondly, impact the test specimen at the predetermined drop block weight (static load) and drop height, then repeat the same test procedure with the other two test specimens. The drop shock acceleration and time curve should be recorded for each test. The average value of peak accelerations for these three drop shock tests is taken as the peak acceleration at the predetermined static load. Thirdly, repeat the drop shock procedure with several more increments of weight until sufficient data are derived to establish the dynamic cushioning curve. Lastly, the same procedure shall be employed for different drop heights. For a drop height, a piece of dynamic cushioning curve may be obtained by making drop shock tests for a range of static loads. Then adjusting the drop height and making similar drop shock tests, another piece of dynamic cushioning curve may be also obtained. Therefore by making a series of drop shock tests for different drop heights, a family of dynamic cushioning curves should be obtained. On the basis of the family of dynamic cushioning curves, the dynamic shock cushioning property of corrugated paperboard pads shall be thoroughly evaluated.

The most comprehensive method for determining vibration transmissibility is described in the standard ASTM D 4168 "Standard test method for vibration transmissibility of package cushioning material". The test procedure is as follows: Firstly, place two specimens combination under investigation in the test fixture, one below and the other above the mass block. The mass block weighted for the desired static load is placed on the bottom test specimen, and the top test specimen is placed above the mass block, then the fixture is clamped in place. Secondly, start the vibration test with slow sine sweep, and present experimental data in the form of vibration transmissibility and frequency curve. In order to thoroughly evaluate the vibration transmissibility of cor- rugated paperboard pads, the range of frequency sweep is selected from $3 \mathrm{~Hz}$ to $600 \mathrm{~Hz}$ in order to wholly investigate on the vibration propery of corrugated paperboard pads. The frequency sweep rate is one octave per minute, and sine excitation acceleration is held constant amplitude at $0.5 \mathrm{~g}$. Thirdly, the same procedure shall be used for different static loads. These different static loads would be selected from the family of dynamic cushioning curves of corrugated paperboard pads. On the basis of vibration transmissibility and frequency curves at different static loads, the vibration transmissibility of corrugated paperboard pads would be investigated.

\section{Results and Discussions}

\subsection{Dynamic Shock Cushioning Property of Corrugated Paperboard Pads}

According to the test method ASTM D 1596, the drop shock tests of corrugated paperboard pads are made for drop heights $30 \mathrm{~cm}, 60 \mathrm{~cm}$ and $90 \mathrm{~cm}$ respectively. The waves of drop shock acceleration are similar to half-sine pulses at different static loads for different drop height, e.g. the wave in Figure 4 is that of single layer pad for drop height (DH) $30 \mathrm{~cm}$ and static load $2.439 \mathrm{kPa}$, the peak acceleration is $177.46 \mathrm{~g}$ (gravity acceleration). In addition Figure 5 provides the wave of two layers pad for drop height $60 \mathrm{~cm}$ and static load $2.613 \mathrm{kPa}$, the peak acceleration is 203.61 g. Figure 6 is the wave of three layers pad while drop height $90 \mathrm{~cm}$ and static load $3.049 \mathrm{kPa}$, the peak acceleration is $291.14 \mathrm{~g}$. Due to the limited space other drop shock acceleration and time curves are omitted.

By comparison studies on the drop shock tests for corrugated paperboard pads, seven pieces of dynamic cushioning curve shall be obtained, which are shown in Figures 7 to 9 . For single layer pad, while the drop height is $60 \mathrm{~cm}$ or $90 \mathrm{~cm}$, the test specimens would be wholly crushed and lose dynamic shock cushioning property, so it has only one piece of dynamic cushioning curve for drop height $30 \mathrm{~cm}$ (Figure 7). The curves in Figure 8 are for two layers pad, and that of Figure 9 are for three layers pad.

These dynamic cushioning curves are the most practical basis for the package cushioning design procedure of corrugated paperboard pads [4-5], so it is necessary to develop experimental formulas of these curves. From the characterization of dynamic cushioning curves summarized above, these curves have a close relationship with the drop height and static stress. When the drop height is constant, the peak acceleration may be described as a function of static stress, and the experimental formulas of dynamic cushioning curves may be established by using the fitting polynomial of curve [17-18]. By comparing 


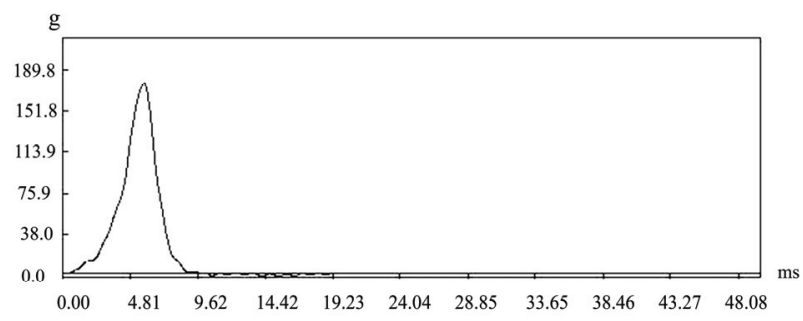

Figure 4. Drop shock acceleration and time curve of single layer pad.

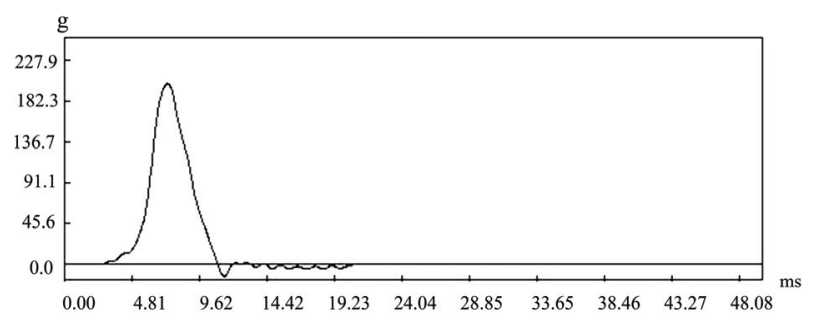

Figure 5. Drop shock acceleration and time curve of two layers pad.

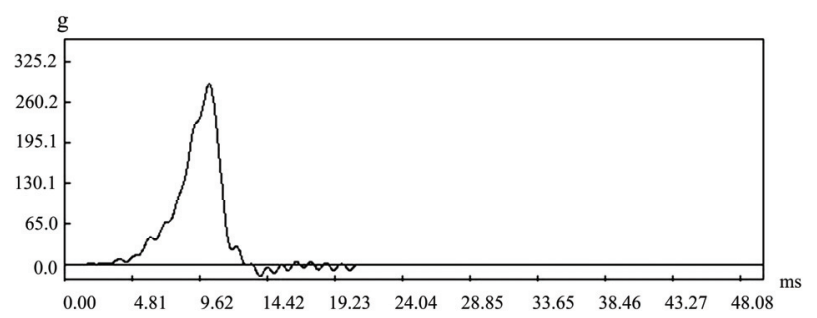

Figure 6. Drop shock acceleration and time curve of three layers pad.

the test data of average peak acceleration with its theoretical data derived from the fitting polynomial of curve, the third order polynomial function of static stress has proved to be the best expression, and the experimental formulas of dynamic cushioning curves of corrugated paperboard pads is written as

$$
G_{m}=a_{0}+a_{1} \sigma_{\mathrm{s}}+a_{2} \sigma_{\mathrm{s}}^{2}+a_{3} \sigma_{\mathrm{s}}^{3}
$$

where $G_{m}$ is average peak acceleration, $\sigma_{s}$ represents static stress, $a_{0}, a_{1}, a_{2}, a_{3}$ are four characteristic factors. For example, Figure 10 gives the dynamic cushioning curve of three layers pad at drop height $60 \mathrm{~cm}$, and the circle dots stand for test data of average peak acceleration. The dynamic cushioning curve is obtained by using the fitting polynomial with third order polynomial function of the curve. So, on the basis of test data of average peak acceleration and static stress obtained from the drop shock tests of corrugated paperboard pads for drop heights $30 \mathrm{~cm}, 60 \mathrm{~cm}$ and $90 \mathrm{~cm}$ respectively, using Equation (7) and Method of the Least Mean Square, the characteristic factors of dynamic cushioning curves are solved and shown in Table 1.

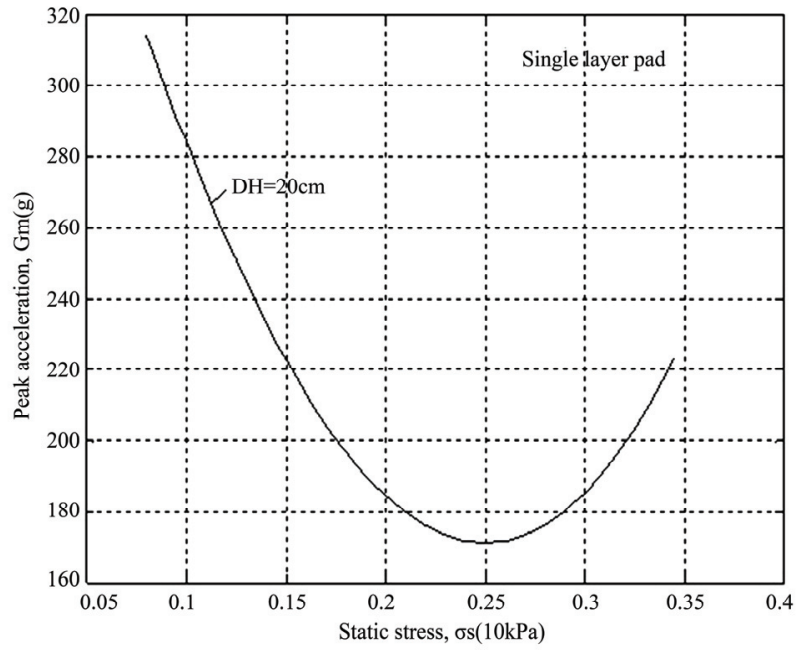

Figure 7. Dynamic cushioning curve of single layer pad.

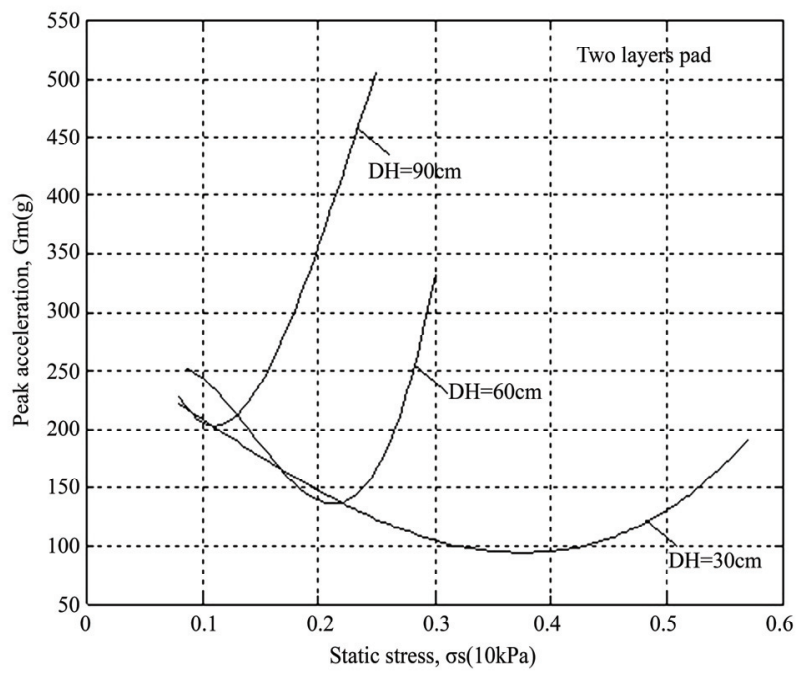

Figure 8. Dynamic cushioning curves of two layers pad.

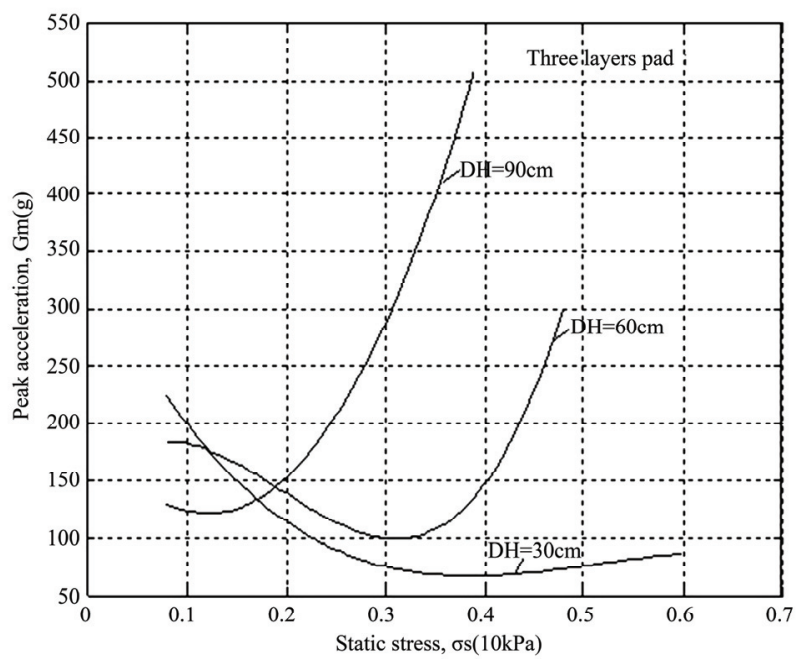

Figure 9. Dynamic cushioning curves of three layers pad. 


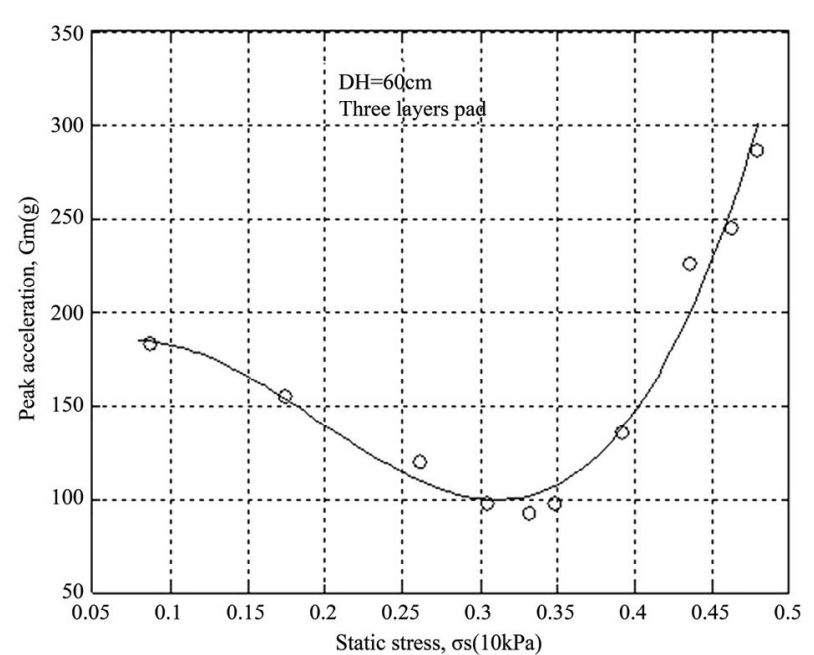

Figure 10. Dynamic cushioning curves of three layers pad $(\mathrm{DH}=60 \mathrm{~cm})$.

By comparing and analyzing these dynamic cushioning curves of corrugated paperboard pads, some conclusions may be drawn as follows:

1) Each piece of dynamic cushioning curves of corrugated paperboard pads (Figures 7-9) is always concave and upward, and has only one minimum value point. This rule can be understood as follows [5]. If the mass of weight and drop block is light, the drop shock would result in very little compressive deformation, and the corrugated paperboard pad absorbs and stores a little mechanical energy per unit volume, so the acceleration peak is relatively large. This represents the left hand side of dynamic cushioning curve. In the middle area, the corrugated paperboard pad is properly compressed and absorbs and stores much mechanical energy per unit volume, so the minimum peak acceleration shall be reached. After passing through a certain point, the greater mass of weight and drop block compresses the corrugated paperboard pad too much, so the corrugated paperboad pad shall be bottomed out, then the minimum peak acceler-

Table 1. Characteristic factors of dynamic cushioning curves.

\begin{tabular}{c|cc}
\hline Pad type & $\begin{array}{c}\text { Drop height } \\
\text { /cm }\end{array}$ & $\mathrm{a}_{0}, \mathrm{a}_{1}, \mathrm{a}_{2}, \mathrm{a}_{3}$ \\
\hline Single layer pad & 30 & $464,-2132.9,3014.3,3325$ \\
\hline & 30 & $273.8,-632.6,-455.9,2299.3$ \\
Two layers pad & 60 & $122.58,4071.8,-37339$, \\
& & 86990 \\
& 90 & $600,-8067,48250,-69897$ \\
\hline & 30 & $344.2,-1796.3,3717.5$, \\
Three layers pad & 60 & $148.07,1004.3,-7969.2$, \\
& & 13630 \\
& 90 & $190.4,-1103.5,4217.2$, \\
& & 1792.7 \\
\hline
\end{tabular}

ation increases. This is the right hand side of the curve. So the middle area of the curve is the optimum performance range.

2) For the same corrugated paperboard pad, with the increment of drop height, the concave point of dynamic cushioning curves (Figures 8 and 9) has a trend to rise along leftward and upward direction. Therefore the drop height is an important factor to influence on the dynamic shock cushioning property, and the selection of dynamic cushioning curve should be coincided with the predetermined drop height in package cushioning design of corrugated paperboard pads.

3) For the same drop height, with the increment of layer quantity of corrugated paperboard pads, the minimum peak acceleration declines. The minimum peak acceleration of three layers pad is least. So three layers pad holds better dynamic shock cushioning property than single layer pad and two layers pad.

\subsection{Vibration Transmissibility of Corrugated Paperboard Pads}

On the basis of the family of dynamic cushioning curves of corrugated paperboard pads (Figures 7 to 9), these different static loads exerted on the bottom test specimen are respectively selected as follows: 1) For single layer pad, four kinds of different static loads, $2.178 \mathrm{kPa}, 2.439 \mathrm{kPa}$, $3.049 \mathrm{kPa}$ and $3.484 \mathrm{kPa}$; 2) For two layers pad, fourteen kinds of different static loads, $0.871 \mathrm{kPa}, 1.132 \mathrm{kPa}$, $1.307 \mathrm{kPa}, 1.568 \mathrm{kPa}, 1.742 \mathrm{kPa}, 2.178 \mathrm{kPa}, 2.439 \mathrm{kPa}$, $2.613 \mathrm{kPa}, 3.049 \mathrm{kPa}, 3.920 \mathrm{kPa}, 4.617 \mathrm{kPa}, 4.791 \mathrm{kPa}$, $5.227 \mathrm{kPa}$ and $5.662 \mathrm{kPa}$; 3) For three layers pad, eleven kinds of different static loads, $0.871 \mathrm{kPa}, 1.307 \mathrm{kPa}$, $1.742 \mathrm{kPa}, 2.178 \mathrm{kPa}, 2.613 \mathrm{kPa}, 3.049 \mathrm{kPa}, 3.310 \mathrm{kPa}$, $3.484 \mathrm{kPa}, 4.356 \mathrm{kPa}, 4.791 \mathrm{kPa}$ and $5.227 \mathrm{kPa}$. According to the test method ASTM D 4168, the vibration tests with slow sine sweep for corrugated paperboard pads at different static loads are made, and the vibration transmissibility and frequency curves are obtained. For example, Figure 11 is the vibration transmissibility and frequency curve of single layer pad at static load $2.439 \mathrm{kPa}$, Figure 12 gives that of two layers pad at static load $4.617 \mathrm{kPa}$, and Figure 13 provides that of three layers pad at static load $4.791 \mathrm{kPa}$. Due to the limited space, other vibration transmissibility and frequency curves are omitted.

On the basis of these vibration transmissibility and frequency curves, resonance frequencies, vibration transmissibility and damping ratios are analyzed by using linear vibration theory with single degree of freedom, and the damping ratios (smaller than one) are estimated by using Equation (6). For example, Table 2 gives the experimental results of single layer pad at static loads of $2.439 \mathrm{kPa}$ and $3.049 \mathrm{kPa}$. Table 3 provides that of two layers pad at static loads of $1.568 \mathrm{kPa}, 2.613 \mathrm{kPa}, 3.920 \mathrm{kPa}, 4.617 \mathrm{kPa}$, 


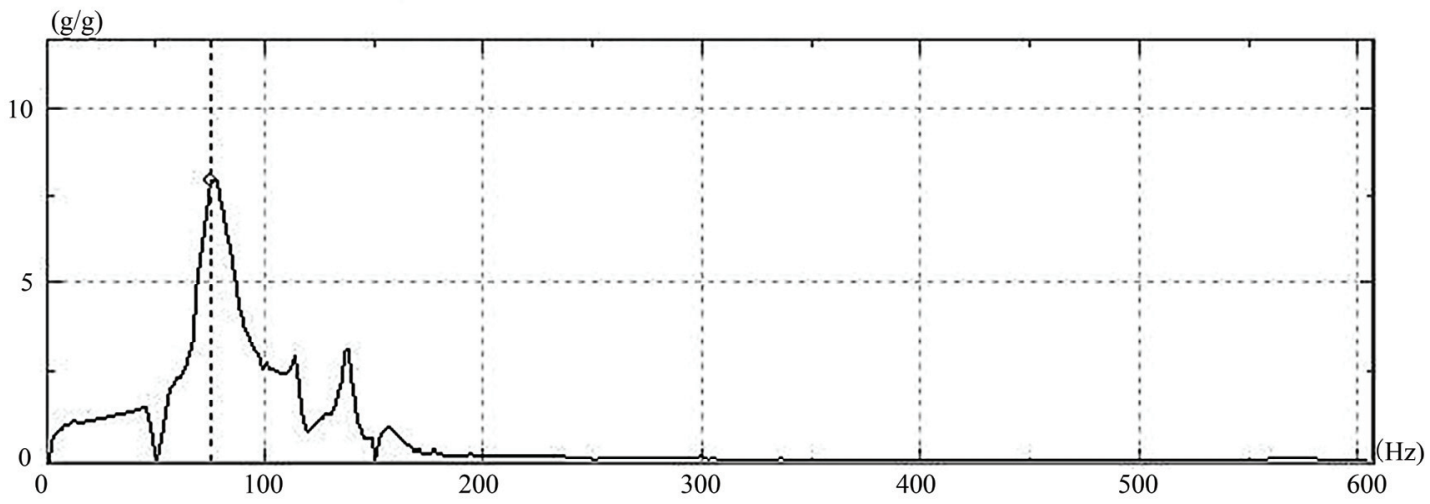

Figure 11. Vibration transmissibility and frequency curve of single layer pad.

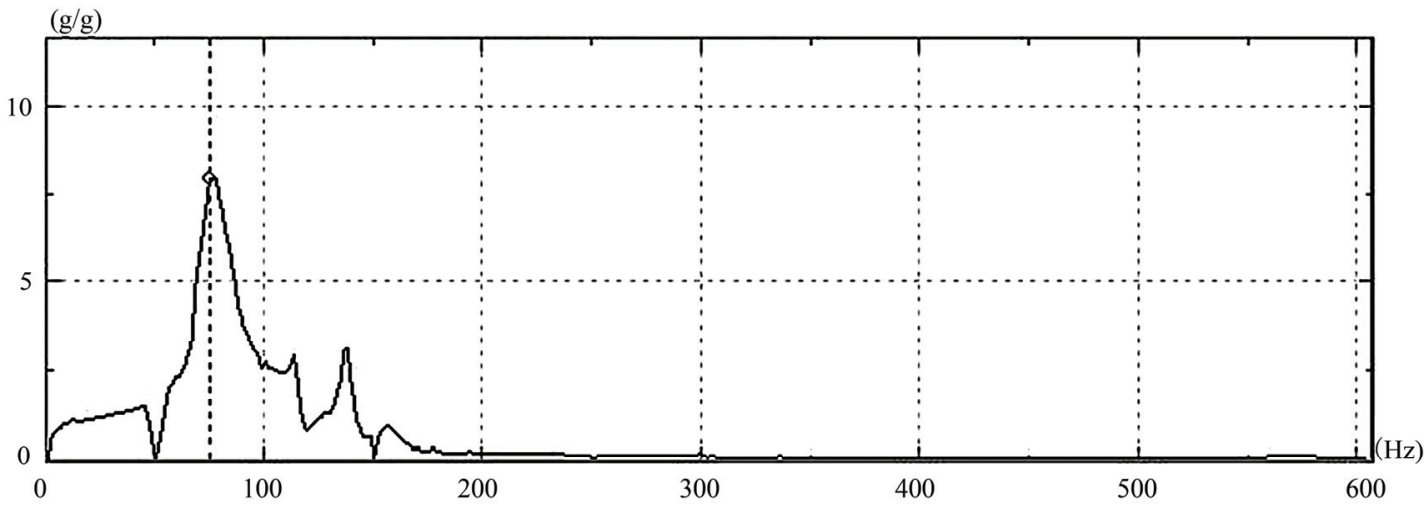

Figure 12. Vibration transmissibility and frequency curve of two layers pad.

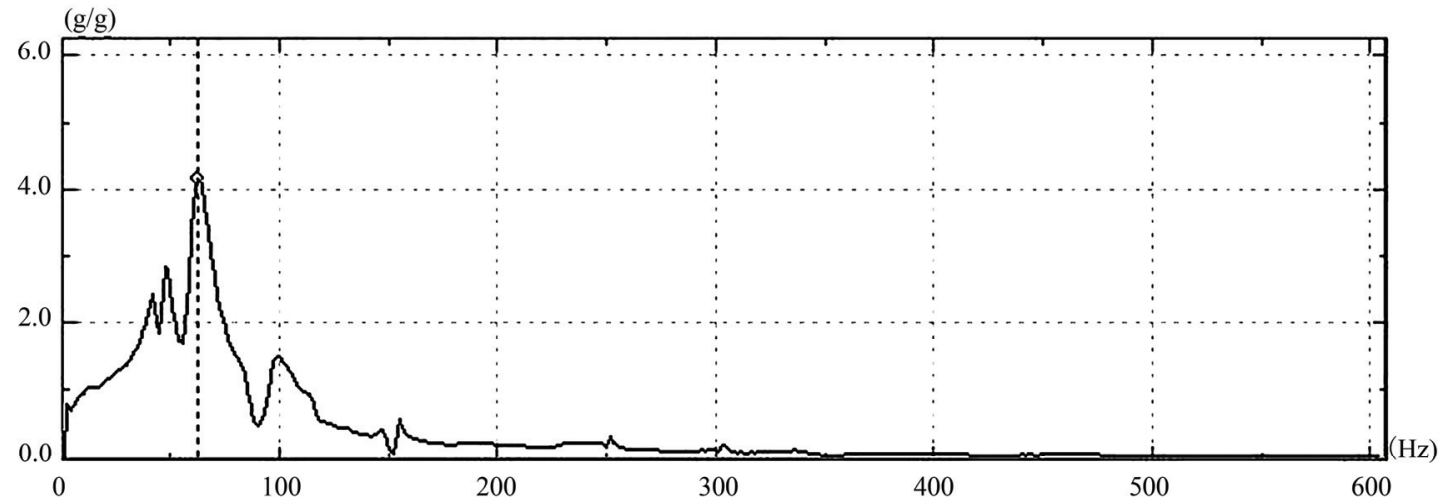

Figure 13. Vibration transmissibility and frequency curve of three layers pad.

$5.227 \mathrm{kPa}$ and $5.662 \mathrm{kPa}$. Table 4 reflects that of three layers pad at static loads of $0.871 \mathrm{kPa}, 2.178 \mathrm{kPa}, 3.049 \mathrm{kPa}$, $4.791 \mathrm{kPa}$ and $5.227 \mathrm{kPa}$. Due to the limited space, other experimental results are omitted.

By comparing and analyzing the experimental results and curves of vibration transmissibility of corrugated paperboard pads at different static loads, some conclu- sions may be reached as follows:

1) The package cushioning system of corrugated paperboard pads has different resonance frequencies, yet only several resonance frequencies are primary and other resonance frequencies have a little effect on the packaged item during distribution. For instance, while static load $4.617 \mathrm{kPa}$ is exerted on two layers pad, the vibration 
Table 2. Vibration transmissibility of single layer corrugated paperboard pad.

\begin{tabular}{cccc}
\hline $\begin{array}{c}\text { Static load } \\
/ \mathrm{kPa}\end{array}$ & $\begin{array}{c}\text { Resonance } \\
\text { Frequency } / \mathrm{Hz}\end{array}$ & $\begin{array}{c}\text { Vibration } \\
\text { transmissibility }\end{array}$ & $\begin{array}{c}\text { Damping } \\
\text { ratio }\end{array}$ \\
\hline & 12 & 0.995 & \\
2.439 & 73 & 1.364 & 0.539 \\
& 97 & 1.814 & 0.330 \\
& 132 & 8.031 & 0.062 \\
& 191 & 2.445 & 0.224 \\
3.049 & 339 & 0.475 & \\
& 12 & 0.985 & \\
& 73 & 1.453 & 0.474 \\
& 97 & 1.966 & 0.295 \\
& 123 & 9.928 & 0.050 \\
& 189 & 2.206 & 0.254 \\
\hline
\end{tabular}

Table 3. Vibration transmissibility of two layers corrugated paperboard pad.

\begin{tabular}{|c|c|c|c|}
\hline $\begin{array}{l}\text { Static load } \\
\qquad / \mathrm{kPa}\end{array}$ & $\begin{array}{c}\text { Resonance } \\
\text { Frequency /Hz }\end{array}$ & $\begin{array}{l}\text { Vibration } \\
\text { transmissibility }\end{array}$ & $\begin{array}{l}\text { Damping } \\
\text { ratio }\end{array}$ \\
\hline \multirow{6}{*}{1.568} & 14 & 1.014 & \\
\hline & 91 & 1.615 & 0.394 \\
\hline & 127 & 3.108 & 0.170 \\
\hline & 167 & 11.214 & 0.045 \\
\hline & 208 & 3.630 & 0.143 \\
\hline & 335 & 0.492 & \\
\hline \multirow{5}{*}{2.613} & 14 & 1.032 & \\
\hline & 38 & 1.742 & 0.351 \\
\hline & 85 & 3.271 & 0.161 \\
\hline & 112 & 5.217 & 0.096 \\
\hline & 280 & 0.515 & \\
\hline \multirow{6}{*}{3.920} & 12 & 1.007 & \\
\hline & 53 & 2.408 & 0.228 \\
\hline & 88 & 7.893 & 0.063 \\
\hline & 102 & 5.574 & 0.090 \\
\hline & 114 & 5.890 & 0.085 \\
\hline & 293 & 0.680 & \\
\hline \multirow{6}{*}{4.617} & 12 & 1.038 & \\
\hline & 45 & 1.416 & 0.499 \\
\hline & 74 & 7.926 & 0.064 \\
\hline & 114 & 2.941 & 0.181 \\
\hline & 138 & 3.121 & 0.169 \\
\hline & 156 & 0.873 & \\
\hline \multirow{6}{*}{5.227} & 14 & 1.039 & \\
\hline & 56 & 2.538 & 0.214 \\
\hline & 70 & 6.416 & 0.078 \\
\hline & 106 & 1.601 & 0.400 \\
\hline & 133 & 1.443 & 0.481 \\
\hline & 153 & 0.458 & \\
\hline \multirow{6}{*}{5.662} & 14 & 1.090 & \\
\hline & 35 & 2.225 & 0.252 \\
\hline & 55 & 2.805 & 0.191 \\
\hline & 76 & 2.122 & 0.267 \\
\hline & 97 & 1.077 & \\
\hline & 121 & 0.425 & \\
\hline
\end{tabular}

transmissibility and frequency curve (Table 3 and Figure 12) has six resonance frequencies such as $12 \mathrm{~Hz}, 45 \mathrm{~Hz}$, $74 \mathrm{~Hz}, 114 \mathrm{~Hz}, 138 \mathrm{~Hz}$ and $156 \mathrm{~Hz}$, their vibration transmissibility are $1.038,1.416,7.926,2.941,3.121$ and 0.873 , respectively. The vibration transmissibility at $74 \mathrm{~Hz}$ is about 9.08 times as much as that of $156 \mathrm{~Hz}$, the vibration transmissibility at $138 \mathrm{~Hz}$ is about 3.58 times as much as that of $156 \mathrm{~Hz}$, so the resonance frequency $74 \mathrm{~Hz}$ should be taken as the first principle mode of vibration, resonance frequency $138 \mathrm{~Hz}$ as the second mode, etc. The result indicates an important guidance that the primary resonance frequencies must be avoided in package cushioning design of corrugated paperboard pads.

2) For the package cushioning system with corrugated paperboard pad, there is critical frequency at which the vibration transmissibility is high, and above the critical frequency the vibration transmissibility drops and is smaller than one. For example, the critical frequency of single layer pad is $191 \mathrm{~Hz}$ (Table 2). When the excitation frequency is higher than $191 \mathrm{~Hz}$, the vibration transmissibility is very low, and the corrugated paperboard pad shall efficiently decrease vibration. In addition, for two layers pad, the critical frequency is $208 \mathrm{~Hz}$ (Table 3), and for three layers pad, the critical frequency is $185 \mathrm{~Hz}$ (Table 4). So the package cushioning system of corrugated paperboard pad may efficiently attenuate vibration with higher excitation frequency during distribution.

3) The static load exerted on the corrugated paperboard pad has an evident influence on vibration transmissibility. The influence relates to the mechanical behavior of corrugated paperboard, especially viscoelasticity. The result suggests another important guidance that the

Table 4. Vibration transmissibility of three layers corrugated paperboard pad.

\begin{tabular}{|c|c|c|c|}
\hline $\begin{array}{l}\text { Static load } \\
/ \mathrm{kPa}\end{array}$ & $\begin{array}{c}\text { Resonance } \\
\text { Frequency } / \mathrm{Hz}\end{array}$ & $\begin{array}{c}\text { Vibration } \\
\text { transmissibility }\end{array}$ & $\begin{array}{l}\text { Damping } \\
\text { ratio }\end{array}$ \\
\hline \multirow{7}{*}{0.871} & 14 & 1.024 & \\
\hline & 71 & 1.500 & 0.447 \\
\hline & 84 & 2.053 & 0.279 \\
\hline & 112 & 3.286 & 0.160 \\
\hline & 138 & 7.633 & 0.066 \\
\hline & 185 & 2.191 & 0.256 \\
\hline & 332 & 0.725 & \\
\hline \multirow{6}{*}{2.178} & 14 & 1.045 & \\
\hline & 61 & 3.969 & 0.130 \\
\hline & 77 & 6.832 & 0.073 \\
\hline & 106 & 3.823 & 0.136 \\
\hline & 127 & 1.288 & 0.616 \\
\hline & 158 & 0.593 & \\
\hline \multirow{6}{*}{3.049} & 14 & 1.042 & \\
\hline & 55 & 2.720 & 0.198 \\
\hline & 74 & 4.744 & 0.108 \\
\hline & 103 & 2.321 & 0.239 \\
\hline & 126 & 1.334 & 0.566 \\
\hline & 152 & 0.387 & \\
\hline \multirow{6}{*}{4.791} & 14 & 1.061 & \\
\hline & 41 & 2.423 & 0.227 \\
\hline & 54 & 2.852 & 0.187 \\
\hline & 62 & 4.192 & 0.123 \\
\hline & 98 & 1.511 & 0.441 \\
\hline & 155 & 0.563 & \\
\hline \multirow{6}{*}{5.227} & 12 & 1.063 & \\
\hline & 47 & 3.482 & 0.150 \\
\hline & 56 & 2.439 & 0.225 \\
\hline & 82 & 2.303 & 0.241 \\
\hline & 105 & 1.152 & 0.874 \\
\hline & 130 & 0.550 & \\
\hline
\end{tabular}


vibration transmissibility and frequency curve must be selected according to the static load exerted on it in package cushioning design of corrugated paperboard pads.

\section{Conclusions}

This research work obtains dynamic cushioning curves, vibration transmissibility and frequency curves of corrugated paperboard pads by a series of experimental studies, and evaluates its dynamic packaging properties relevant to its application for protective packaging such as dynamic shock cushioning property and vibration transmissibility. The waves of drop shock acceleration are similar to half-sine pulses, the shapes of dynamic cushioning curves are always concave and upward, and each piece of dynamic cushioning curves has only one minimum value point. The package cushioning system of corrugated paperboard pads has different resonance frequencies, and only several resonance frequencies are primary. The results show that corrugated paperboard pads possess dynamic shock cushioning property for drop shock, and the three layers pad has better dynamic shock cushioning property than single layer pad and two layers pad. For the package cushioning system with corrugated paperboard pads, there is critical frequency at which the vibration transmissibility is high, and above the critical frequency the vibration transmissibility drops and is smaller than one. The critical frequency of single layer pad is $191 \mathrm{~Hz}$, that of two layers pad is $208 \mathrm{~Hz}$, and that of three layers pad is $185 \mathrm{~Hz}$. The package cushioning system of corrugated paperboard pad may efficiently attenuate vibration with higher excitation frequency during distribution.

\section{Acknowledgements}

This research work is supported by the Scientific Research Foundation of Science and Technology Department of Shaanxi Province under the Grant 2007K07 - 21 and the Scientific Research Foundation of Printing \& Packaging Material and Technology Beijing Area Major Laboratory under the Grant KF200705. We would like to thank Northwest Corrugated Paperboard Limited Company for providing test specimens of corrugated paperboard pads.

\section{References}

[1] G. W. Kooistra, V. Deshpande and H. N. G. Wadley, "Hierarchical Corrugated Core Sandwich Panel Concepts," Journal of Applied Mechanics, Vol. 74, No. 1, 2007, pp. 259-268.

[2] J. Kirkpatrick and M. Sek, "Replacement of Polymeric Cushioning with Corrugated Fiberboard-Case Study," Proceedings of 10th IAPRI World Conference on Packaging, Melbourne, Australia, 1997, pp. 267-276.
[3] R. D. Mindlin, "Dynamics of Package Cushioning," Bell System Technical Journal, Vol. 24, No. 7-10, 1945, pp. 353-461.

[4] G. S. Mustin, "Theory and Practice of Cushion Design," The Shock and Vibration Information Center, U.S. Department of Defense, 1968.

[5] U. S. Department of Defense, "Military Standardization Handbook, Package Cushioning Design (MIL-HDBK304B)," 1978.

[6] E. K. Hahn, A. D. Rudo, B. S. Westerlind and L. A. Carlsson, "Compressive Strength of Edge-Loaded Corrugated Board Panels," Experimental Mechanics, Vol. 32, No. 3, 1992, pp. 259-265.

[7] M. H. Lee and J. M. Park, "Flexural Stiffness of Selected Corrugated Structures," Packaging Technology and Science, Vol. 17, No. 5, 2004, pp. 275-286.

[8] T. J. Urbanik, "Effect of Corrugated Flute Shape on Fiberboard Edgewise Crush Strength and Bending Stiffness," Journal of Pulp and Paper Science, Vol. 27, No. 10, 2001, pp. 330-335.

[9] Y. F. Guo, Y. G. Fu and W. Zhang, "Creep Properties and Recoverability of Double-Wall Corrugated Paperboard," Experimental Mechanics, Vol. 48, No. 3, 2008, pp. 327-333.

[10] A. C. Gilchrist, J. C. Suhling and T. J. Urbanik, "Nonlinear Finite Element Modeling of Corrugated Board," Proceedings of International Conference on Mechanics of Cellulosic Materials, Virginia, USA, 1999, pp. 101-106.

[11] T. Nordstrand and A. Allansson, "Stability and Collapse of Corrugated Board Panels, Numerical and Experimental Analysis," Proceedings of 6th International Conference on Sandwich Structures, Florida, USA, 2003, pp. 202-210.

[12] Z. Aboura, N. Talbi, S. Allaoui and M. L. Benzeggaph, "Elastic Behavior of Corrugated Cardboard: Experiments and Modeling," Composite Structures, Vol. 63, No. 1, 2004, pp. 53-62.

[13] H. A. Rami, J. Choi, B. S. Wei, R. Popil and M. Schaepe, "Refined Nonlinear Finite Element Models for Corrugated Fiberboards," Composite Structures, Vol. 87, No. 4, 2009, pp. 321-333.

[14] N. Talbi, A. Batti, R. Ayad and Y. Q. Guo, "An Analytical Homogenization Model for Finite Element Modeling of Corrugated Cardboard," Composite Structures, Vol. 88, No. 2, 2009, pp. 280-289.

[15] M. Sek and J. Kirkpatrick, "Characteristics of Corrugated Fiberboard as a Cushioning Material in Protective Packaging," Proceedings of 10th IAPRI World Conference on Packaging, Melbourne, Australia, 1997, pp. 257-266.

[16] M. Sek and J. Kirkpatrick, "Prediction of the Cushioning Properties of Corrugated Fiberboard from Static and Quasidynamic Compression Data," Packaging Technology and Science, Vol. 10, No. 2, 1997, pp. 87-94.

[17] G. Burgess, "Generation of Cushion Curves from One Shock Pulse," Packaging Technology and Science, Vol. 7, No. 2, 1994, pp. 169-173.

[18] Y. F. Guo and J. H. Zhang, "Shock Absorbing Characteristics and Vibration Transmissibility of Honeycomb Pa perboard," Shock and Vibration, Vol. 11, No. 5-6, 2004, pp. 521-531. 